\title{
Left ventricular hypertrophy in presence of complete left bundle-branch block*
}

\author{
RONALD W ZMYSLINSKI, J FRANKLIN RICHESON, TOSHIO AKIYAMA
}

From the Cardiology Unit, Department of Medicine, University of Rochester Medical Center, Rochester, New York, USA

SUMMARY Electrocardiograms of 2500 consecutive patients who died in hospital were reviewed in order to study the relation of complete left bundle-branch block to pathological determinants of anatomical left ventricular hypertrophy. Of these, 43 patients demonstrated complete left bundle-branch block and all but two had anatomical left ventricular hypertrophy at necropsy.-Mean values of total heart weight and percentage total heart weight of normal were significantly higher in this group of 43 patients with complete left bundle-branch block than in a control necropsy group of 300 patients with anatomical left ventricular hypertrophy but without complete left bundle-branch block. Left ventricular wall thickness did not correlate with other measures of left ventricular muscle mass. Commonly used electrocardiographic voltage criteria for left ventricular hypertrophy identified approximately one-half of the 41 patients with left bundle-branch block and anatomical left ventricular hypertrophy. The degree of electrocardiographic voltage abnormality correlated modestly with total heart weight and percentage total heart weight of normal. A group of 25 patients was studied in whom electrocardiograms were available before and after complete left bundle-branch block. Normal voltage before left bundlebranch block tended to remain normal, while abnormally high voltage tended to fall after complete left bundle-branch block developed. Complete left bundle-branch block in a necropsy population characterised a group with extreme anatomical left ventricular hypertrophy. The sensitivity of the usual electrocardiographic left ventricular hypertrophy voltage criteria in the presence of complete left bundlebranch block is only slightly less than in patients with left ventricular hypertrophy alone. The degree of electrocardiographic voltage abnormality with complete left bundle-branch block shows modest correlation with degree of anatomical left ventricular hypertrophy.

Opinions vary as to whether or not the electrocardiographic diagnosis of left ventricular hypertrophy can be made when complete left bundlebranch block coexists. ${ }^{1-3}$ Few data have been reported on the subject, and reports suffer somewhat from lack of clear definition of methods and terminology. The issue may be of more than academic interest when one considers that left ventricular hypertrophy may be missed by routine chest $x$-ray film $^{4}$ and physical examination. ${ }^{5}$ Though other clinical modalities, that is angiography and echocardiography are also available for assessment of left ventricular mass, the cornerstones *This study was supported in part by a grant from the National Heart, Lung and Blood Institute, National Institutes of Health, Bethesda, Maryland; Genesee Valley Heart Association Research Fellowship Grant, Rochester, New York; and grant-in-aid from the Genesee Valley Heart Association. Presented in part at the 50th Scientific Sessions, American Heart Association, Miami Beach, Florida, 30 November 1977.

Received for publication 14 July 1979 for the diagnosis of left ventricular hypertrophy remain the chest $x$-ray film, physical examination, and electrocardiogram in most routine clinical settings.

The purpose of this report is to explore further how well currently employed electrocardiographic criteria for the diagnosis of left ventricular hypertrophy can be applied to a group of patients at necropsy who had complete left bundle-branch block. We also examine the electrocardiograms of a group of patients before and after the development of complete lett bundle-branch block assessing its effect on the QRS voltage.

\section{Methods}

Electrocardiograms of 2500 consecutive patients who died at Strong Memorial Hospital in Rochester, New York, during the years 1972 to 1976 were 
reviewed. Records were selected for study if the patient was 21 years or older and if complete left bundle-branch block was recorded within six months of death. Patients who developed complete left bundle-branch block as a terminal event (within 24 hours of death) were excluded. All the following criteria were required for the diagnosis of complete left bundle-branch block: (1) documented atrioventricular conduction, (2) absence of Wolff-Parkinson-White syndrome, (3) QRS duration in any lead $\geqslant 120 \mathrm{~ms}$, (4) intrinsicoid deflection $\geqslant 50 \mathrm{~ms}$ in the left heart leads, (5) deformity of the $R$ wave in the left heart leads consisting of slurred, notched, flat, or bifid $R$ wave, (6) major fraction of the QRS duration in the left heart leads occupied by the $R$ wave, (7) absence of significant $Q$ waves in any left heart lead, ${ }^{6}(8)$ absence of a large $S$ wave $(\geqslant 20 \%$ of the total QRS deflection) in any left heart lead, and (9) ST segment depression and/or $T$ wave inversion in the left heart leads.

The 43 patients that met the above criteria were subdivided into (a) a group of 32 patients with persistent complete left bundle-branch block (present for at least six months without intervening normal conduction) or left bundle-branch block of indeterminate onset and (b) a group of 11 patients in whom the onset of complete left bundle-branch block occurred within six months of death or in whom it was intermittent. The former group of 32 patients is termed persistent complete left bundlebranch block for the sake of conciseness, while the latter group of 11 patients is termed intermittent left bundle-branch block, though, strictly speaking, some of these simply represent recent onset left bundle-branch block.

As a control group, the electrocardiograms and findings at necropsy of all patients age 21 years or more who came to necropsy during the first three months of each year during the study period 197276 were reviewed.
The total heart weight, left ventricular wall thickness, body length, and sex were recorded at necropsy. Normal predicted total heart weight was defined according to the tables of Zeek, ${ }^{7}$ and any heart weight two standard deviations above the mean of normal was regarded as anatomical left ventricular hypertrophy. Percentage total heart weight of normal was calculated for each patient at necropsy by dividing the recorded total heart weight by the predicted value. This measurement allows correction of total heart weight for sex and body length.

One investigator coded by number all electrocardiograms without knowledge of the results of the necropsies. The following electrocardiographic measurements (paper speed $25 \mathrm{~mm} / \mathrm{s}$, sensitivity $1 \mathrm{mV} / 10 \mathrm{~mm}$ ) were then recorded by blinded observers: (1) height ( $\mathrm{mV}$ of $\mathrm{R}$ waves in leads I, II, II, aVL, aVF, and V1 to V6; (2) depth (mV) of S waves in leads I, II, III, aVL, aVF, V1 to V6; (3) intrinsicoid deflection ( $\mathrm{ms}$ ) from the left heart leads; (4) maximum QRS width (ms) from any lead; and (5) mean QRS axis. Electrocardiographic voltage criteria for left ventricular hypertrophy were reviewed, and those criteria shown by Romhilt and co-workers ${ }^{8}$ to have a higher predictive value for left ventricular hypertrophy were tested. Electrocardiogram and necropsy data were transferred to IBM punch cards for computerised statistical analysis.

Electrocardiographic variables were compared with pathological determinants of left ventricular hypertrophy using standard correlational analyses. Student $t$ tests (two-sided) were used to compare pathological determinants of left ventricular hypertrophy in the various subgroups of patients at necropsy. McNemar's test (exact version) was employed to determine statistically significant change in electrocardiographic variables before and after development of complete left bundle-branch

Table 1 Identification of patient groups

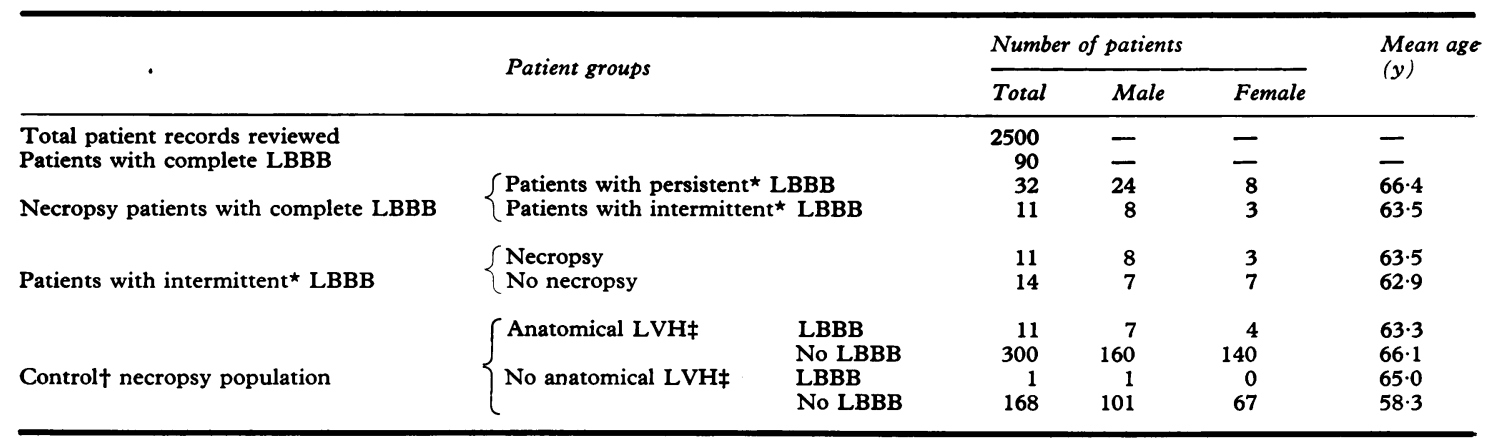

* See text for definition of persistent and intermittent LBBB. † Control (base) necropsy population defined in text. $¥$ Anatomical LVH is described in text. LBBB, left bundle-branch block; LVH, left ventricular hypertrophy. 
block in a group of 25 patients in whom both types of electrocardiograms were available within six months of each other.

\section{Results}

The sex and mean age of the patient groups are shown in Table 1 . Forty-three of 90 patients (47.7\%) who died with complete left bundle-branch block came to necropsy. The average percentage of necropsy examinations for the entire hospital population during this period of study was $53 \cdot 2$.

Table 2 Clinicopathological findings in 43 patients with complete left bundle-branch block and necropsy

\begin{tabular}{lcc}
\hline Diagnosis & Number & Per cent \\
\hline Old or recent myocardial infarction & 31 & $72 \cdot 1$ \\
Aortic valve diseaset & 4 & $9 \cdot 3$ \\
Cardiomyopathy & 4 & $9 \cdot 3$ \\
Normal heart & 2 & $4 \cdot 6$ \\
Pulmonary embolism & 1 & $2 \cdot 3$ \\
Cor pulmonale & 1 & $2 \cdot 3$ \\
\hline Total & 43 & $100 \cdot 0$ \\
\hline
\end{tabular}

* Significant hypertension was additionally present in five of tnese patients + An additional five patients had significant aortic valve disease in association with old or recent myocardial infarction and are included in the latter category.

Of the patients with complete left bundle-branch block, 41 of $43(95.3 \%)$ had evidence of anatomical left ventricular hypertrophy on the basis of total heart weight and percentage total heart weight of normal. Left ventricular wall thickness showed no correlation with total heart weight $(r=-0.05)$ and percentage total heart weight of normal $(r=-0.05)$.

The control necropsy group consisted of 480 patients, $311(64.8 \%)$ of whom were found to have anatomical left ventricular hypertrophy; 12 of 480 $(2.5 \%)$ also showed complete left bundle-branch block within six months of death. Only one of the 169 control patients without left ventricular hypertrophy had left bundle-branch block, while 11 of the 311 control patients with left ventricular hypertrophy had left bundle-branch block.

Table 2 summarises the clinical information of 43 patients with complete left bundle-branch block at necropsy.

Table 3 summarises the comparison of mean relative heart weights in the groups of patients mentioned. The entire group of 43 patients with left bundle-branch block and the subgroup of 32 patients with persistent left bundle-branch block both demonstrate a significantly higher mean relative heart weight than do the subgroup of 11 patients with intermittent left bundle-branch block and the group of 300 control patients with anatomi-
Table 3 Comparison of percentage total heart weight of normal in groups of patients with and without complete left bundle-branch block

\begin{tabular}{lll}
\hline Group & $\begin{array}{l}\text { Number of } \\
\text { patients }\end{array}$ & $\begin{array}{l}\text { Percentage total } \\
\text { heart weight of } \\
\text { normal } \pm S D\end{array}$ \\
\hline Complete LBBB & 43 & $200 \cdot 4 \pm 49 \cdot 9 \star$ \\
Persistent $\star$ LBBB & 32 & $209 \cdot 7 \pm 54 \cdot 3^{\star}$ \\
Intermittent† LBBB & 11 & $175 \cdot 6 \pm 37 \cdot 8$ \\
LVH but no LBBB (control) & 300 & $169 \cdot 1 \pm 36 \cdot 2$
\end{tabular}

*Significantly higher than in the last two groups $(P<0.05)$. tSee text for definition of persistent and intermitrent LBBB.

LBBB, left bundle-branch block; LVH, left ventricular

hypertrophy; SD, standard deviation.

cal left ventricular hypertrophy but no left bundlebranch block $(P<0.05)$.

Table 4 shows the results of application of currently employed electrocardiographic voltage criteria for left ventricular hypertrophy to the group of 41 patients with complete left bundle-branch block and anatomical left ventricular hypertrophy. A comparison of the expected frequency of abnormality (on the basis of Romhilt et al.' $s^{8}$ data for patients with left ventricular hypertrophy but no left bundle-branch block with observed frequency of abnormality is shown. The data reveal only a minor loss of sensitivity of these criteria in our group of patients with complete left bundle-branch block.

Table 4 Frequency of abnormality of left ventricular hypertrophy voltage criteria in 41 patients with complete left bundle-branch block and anatomical left ventricular hypertrophy

\begin{tabular}{llll}
\hline Voltage criteria & $\begin{array}{l}\text { Normal } \\
\text { value } \\
(\mathrm{mm})\end{array}$ & $\begin{array}{l}\text { Observed } \\
\text { frequency of } \\
\text { abnormality } \\
(\%)\end{array}$ & $\begin{array}{l}\text { Expected } \\
\text { frequency } \\
\text { abnormality } \\
(\%)\end{array}$ \\
\hline RaVL & $\leqslant 7.5$ & 46.3 & 22.5 \\
(RI + SIII) - (RIII + SI) & $<17.0$ & 26.8 & 17.5 \\
SV1 or SV2 +RV5 & $<35.0$ & 51.2 & 56.3 \\
SV1 or SV2 + RV5 or RV6 & $\leqslant 35.0$ & 53.7 & 55.6 \\
R+St & $\leqslant 40.0$ & 48.8 & 55.0 \\
RS & $\leqslant 35.0$ & 36.6 & 40.6 \\
SV1 or SV2 & $<30.0$ & 34.1 & - \\
SV1 or SV2 or SV3 & $\leqslant 30.0$ & 34.1 & - \\
RV5 or RV6 & $<30.0$ & 4.9 & - \\
SV1 or SV2 or SV3 or & $<40.0$ & 48.8 & - \\
RV5 or RV6 & & & - \\
\hline
\end{tabular}

* From data by Romhilt et al. ${ }^{8}$ in patients with anatomical left ventricular hypertrophy but no left tundle-branch block.

+ Sum of largest $R$ wave and largest $S$ wave in unipolar praecordial leads. ¥ Largest total RS deflection in any unipolar lead.

Table 5 shows the correlation of three voltage criteria (two of which were the most sensitive as found in this study) with the total heart weight, percentage total heart weight of normal, and left ventricular wall thickness of the 41 patients with 
Table 5 Correlation of electrocardiographic variables with measures of anatomical left ventricular hypertrophy in 41 patients with complete left bundle-branch block and anatomical left ventricular hypertrophy

\begin{tabular}{|c|c|c|c|}
\hline \multirow{2}{*}{$\begin{array}{l}\text { Electrocardiogram } \\
\text { variable }\end{array}$} & \multicolumn{3}{|c|}{ Correlation with } \\
\hline & $\begin{array}{l}\text { Absolute } \\
\text { heart } \\
\text { weight }\end{array}$ & $\begin{array}{l}\text { Relative } \\
\text { heart weight } \\
\text { (percentage } \\
\text { of normal) }\end{array}$ & $\begin{array}{l}\text { Left } \\
\text { ventricular } \\
\text { wall } \\
\text { thickness }\end{array}$ \\
\hline $\begin{array}{l}\text { RaVL } \\
\text { SV1 or SV2 + RV6 } \\
\text { SV1 or SV2 + RV5 or RV6 } \\
\text { Max. QRS width } \\
\text { Intrinsicoid deflection }\end{array}$ & $\begin{array}{l}0.375^{\star} \\
0.346^{\star} \\
50.373^{\star} \\
0.014 \\
0.155\end{array}$ & $\begin{array}{l}0.370^{\star} \\
0.359^{\star} \\
0.407^{\star} \\
0.008 \\
0.216\end{array}$ & $\begin{array}{r}0.212 \\
0.218 \\
0.184 \\
-0.211 \\
0.090\end{array}$ \\
\hline
\end{tabular}

* Significant at 5 per cent level.

complete left bundle-branch block and anatomical left ventricular hypertrophy. Left ventricular wall thickness showed no significant correlation with any of the electrocardiographic variables listed. All three voltage criteria correlated modestly with the measures of absolute and relative heart weight. There was no significant correlation of maximum QRS width or intrinsicoid deflection to any of the measurements of anatomical left ventricular hypertrophy.

Fourteen of the 43 patients with complete left bundle-branch block and necropsy showed a normal QRS axis, that is a mean QRS axis between -29 and +119 degrees, on their premortem electrocardiograms, while 29 showed left axis deviation, that is a mean QRS axis equal to or greater than -30 degrees. There was no correlation of mean QRS axis with total heart weight $(r=-0.07)$ or percentage total heart weight of normal $(r=-0.05)$ in the entire group of 43 patients.

Analysis of the 25 patients with electrocardiograms recorded before and after the development of complete left bundle-branch block within six months of each other disclosed that the most sensitive voltage criteria found in our study (SV1 or SV2+RV5, SV1 or SV2+RV5 or RV6, and $\mathbf{R}+\mathbf{S}$ ) when abnormal before left bundle-branch block tended to become normal after the development of left bundle-branch block $(P<0.05)$. When these three voltage criteria were normal before left bundle-branch block, they tended to remain normal after left bundle-branch block developed (Fig.). No clear pattern of change was noted in the other electrocardiographic criteria tested.

\section{Discussion}

The high incidence of anatomical left ventricular hypertrophy in 43 patients with complete left bundle-branch block $(95.3 \%)$ is not surprising since almost all our patients with left bundle-branch block had other associated cardiovascular disease. The strong association of anatomical left ventricular hypertrophy and other cardiovascular disease (especially hypertension and coronary artery disease) in patients with complete left bundle-branch block has been noted by others. ${ }^{9-11}$ The severity of anatomical left ventricular hypertrophy in our population of 43 patients was unexpected. Mean heart weights and relative heart weights were twice normal predicted values. Furthermore, the mean heart weight of the 43 patients with complete left bundle-branch block was significantly higher $(P<0.05)$ than the mean heart weight of the 300 control necropsy patients with anatomical left ventricular hypertrophy but without complete left bundle-branch block. Interestingly, the mean heart weight in the subgroup of 11 patients with intermittent and recent onset left bundle-branch block was significantly lower $(P<0.05)$ than in the subgroup of 32 patients with persistent and indeterminate onset left bundle-branch block. This suggests, though does not prove, a progression of anatomical left ventricular hypertrophy in association with the development of complete left bundlebranch block.

Although sensitivity of currently employed electrocardiographic voltage criteria for left ventricular hypertrophy is relatively low when applied to our population of 41 patients with complete left
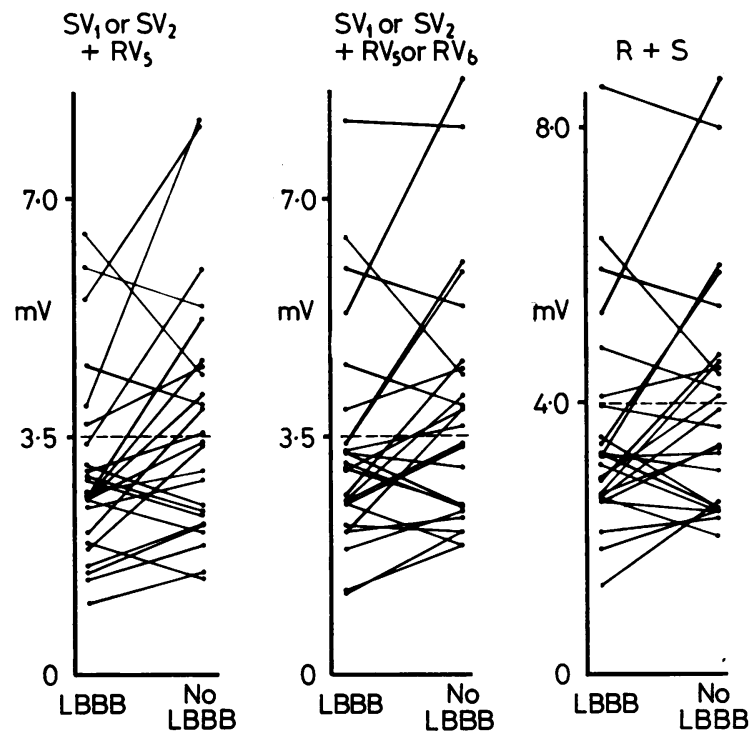

Fig. Change in electrocardiographic voltage in 25 patients before and after development of complete left bundle-branch block. 
bundle-branch block and anatomical left ventricular hypertrophy $(26.8 \sim 53.7 \%)$, the sensitivity is only slightly less than when the same criteria are applied to a group of patients with anatomical left ventricular hypertrophy but without left bundle-branch block (17.5 56.3\%) according to Romhilt et al.' $\mathrm{s}^{8}$ data. Pathological criteria for anatomical left ventricular hypertrophy in our study differ from those used by Romhilt et al. ${ }^{8}$ who used weight of the isolated left ventricle as the criterion for anatomical left ventricular hypertrophy while we used total heart weight and total heart weight corrected for sex and body length as suggested by Zeek. ${ }^{7}$ Perhaps the sensitivity of the electrocardiographic voltage criteria we tested would have differed had we employed the same pathological method as Romhilt's group. Weight of the separated left ventricle appears to be a superior pathological measure of anatomical left ventricular hypertrophy than total heart weight even if the total heart weight is corrected for sex and body length, though most necropsy laboratories (including ours) do not employ this technique. ${ }^{12} 13$ Pathologically, left ventricular wall thickness has not been shown to correlate well with any other indices of left ventricular muscle mass, ${ }^{12-14}$ and the absence of correlation of this measurement in our study with electrocardiographic and other pathological criteria of left ventricular hypertrophy supports this observation. Our data regarding the sensitivity of various electrocardiographic voltage criteria for left ventricular hypertrophy in the presence of complete left bundle-branch block tend to parallel the recent findings of Cokkinos et al. ${ }^{3}$ who showed good correlation of pre- and post-left bundle-branch block Sokolow index values in a group of 40 patients with intermittent complete left bundlebranch block.

Interestingly, if one employs our most sensitive electrocardiographic voltage criteria as shown in the Fig. to the group of 25 patients with pre- and post-left bundle-branch block electrocardiograms, patients without electrocardiographic voltage criteria for left ventricular hypertrophy before the development of complete left bundle-branch block tend to retain normal voltage after complete left bundlebranch block develops while those with abnormally high voltage before left bundle-branch block tend to lose it after complete left bundle-branch block develops. This observation, plus the fact that our most sensitive electrocardiographic voltage criteria correlate modestly with total heart weight and percentage total heart weight of normal in 41 patients with both anatomical left ventricular hypertrophy and complete left bundle-branch block, suggest that when abnormal electrocardiographic voltage remains in a patient with complete left bundle-branch block, anatomical left ventricular hypertrophy must certainly be suspected. The mere presence of complete left bundle-branch block in our population is associated with extreme left ventricular hypertrophy in nearly all (95.3\%) patients. Perhaps, though not very sensitive, the presence of complete left bundle-branch block may be a specific marker of underlying anatomical left ventricular hypertrophy as judged by our study and that of Scott's. ${ }^{15}$ Exact specificity of the electrocardiographic variables for left ventricular hypertrophy in the presence of complete left bundle-branch block cannot be accurately gauged by this study since only two of 43 patients with complete left bundle-branch block were found not to have anatomical left bundle-branch block.

We were unable to show a difference in total heart weight and percentage total heart weight of normal between patients with complete left bundlebranch block and normal QRS axis and patients with complete left bundle-branch block and left axis deviation. However, recent data ${ }^{10}$ suggest that patients with both complete left bundle-branch block and left axis deviation experience more severe cardiac diseases, with more deaths from cardiovascular events than do patients with complete left bundle-branch block but with normal QRS axis.

The population sampled by our study differs considerably from the population of all persons with left bundle-branch block, and caution must be exercised in extending these findings to that population. A group of generally younger patients has been described ${ }^{16}{ }^{17}$ who have complete left bundle-branch block but no other evidence of heart disease. The magnitude and status of this group are of principal interest. Since such patients were rarely encountered $(1 / 12$ of those with complete left bundle-branch block) in our control necropsy population of 480 patients, it appears that they either comprise a very small portion of the population of persons with left bundle-branch block or that they develop anatomical left ventricular hypertrophy at a higher rate than persons without left bundle-branch block. Perhaps some of the population of young persons with asymptomatic complete left bundle-branch block do indeed have a degree of anatomical left ventricular hypertrophy not detectable clinically, or longer follow-up. of these persons would eventually reveal that anatomical left ventricular hypertrophy develops as a result of previously undetected associated heart disease. 


\section{References}

${ }^{1}$ Laham J, Gialloreto O, Lenegre J. Electrocardiographic diagnosis of ventricular hypertrophy in bundle branch block. Acta Cardiol (Brux) 1951 ; 6: 129-49.

'Petersen GV, Tikoff G. Left bundle branch block and left ventricular hypertrophy: electrocardiographicpathologic correlations. Chest 1971; 59: 174-7.

${ }^{3}$ Cokkinos DV, Demopoulos JN, Heimonas ET, Mallios C, Papazoglou N, Vorides EM. Electrocardiographic criteria of left ventricular hypertrophy in left bundle-branch block. Br Heart f 1978; 40: 320-4.

Weens HS, Gay BB. (1974) Radiologic examination of the heart. In: Hurst JW, Logue RB, Schlant RC, Wenger $\mathrm{NK}$, eds. and $\mathrm{N}$. $\mathrm{K}$. Wenger The heart, arteries and veins. New York: McGraw-Hill, 1974: 323. ${ }^{5}$ Eddleman EE Jr. Examination of the precordial movements. In: Hurst JW, Logue RB, Schlant RC, Wenger NK, eds. The heart, arteries and veins. New York: McGraw-Hill, 1974; 323.

'Rose GA, Blackburn H. Cardiovascular survey methods. Geneva: World Health Organisation, 1968.

'Zeek PM. Heart weight. Arch Pathol 1942; 34: 820-32.

${ }^{8}$ Romhilt DW, Bove KE, Norris RJ, et al. A critical appraisal of the electrocardiographic criteria for the diagnosis of left ventricular hypertrophy. Circulation 1969; 40: 185-95.

'Rasmussen H, Moe T. Pathogenesis of left bundle branch block. Br Heart f 1948; 10 : 141-7.

${ }^{10}$ Dhingra RC, Amat-y-Leon F, Wyndham C, et al. Significance of left axis deviation in patients with chronic left bundle branch block. Am $\mathcal{F}$ Cardiol 1978; 42: 551-6.
"Schneider JF, Thomas HE Jr, Kreger BE, McNamara PM, Kannel WB. Newly acquired left bundle-branch block: the Framingham study. Ann Intern Med 1979; 90: 303-10.

${ }^{12}$ Reiner L. Gross examination of the heart. In: Gould SE, ed. Pathology of the heart and blood vessels. Springfield, Illinois: Charles C Thomas, 1968: 1111.

${ }^{13}$ Davies MJ, Pomerance A, Lamb D. Techniques in examination and anatomy of the heart. In: Pomerance A, Davies MJ, eds. The pathology of the heart. Oxford: Blackwell Scientific Publications, 1975: 1.

${ }^{14}$ Smith HL. The relation of the weight of the heart to the weight of the body and of the weight of the heart to age. Am Heart $\mathcal{F} 1928$; 4: 79-93.

${ }^{15}$ cott RC, Norris RJ. Electrocardiographic-pathologic correlation study of left ventricular hypertrophy in the presence of left bundle-branch block. Circulation 1959; 20: 766-7.

${ }^{16}$ Lamb LE, Kable KD, Averill KH. Electrocardiographic findings in 67,375 asymptomatic subjects. V. Left bundle branch block. Am $\mathcal{f}$ Cardiol 1960; 6: $130-42$.

${ }^{17}$ Lamb LE, Johnson RL. Left bundle branch block in flying personnel. A report of 56 cases. Aerosp Med 1964; 35: 97-104.

Requests for reprints to Dr Ronald W Zmyslinski, University of South Carolina School of Medicine, Veterans Administration Hospital Enclave, Columbia, South Carolina 29201, USA. 